\title{
Sensitivity of arid/humid patterns in China to future climate change under a high-emissions scenario
}

\author{
MA Danyang ${ }^{1,2,3}$, DENG Haoyu ${ }^{1,2},{ }^{*}$ YIN Yunhe $^{1}$, WU Shaohong ${ }^{1,2}$, ZHENG Du ${ }^{1,2}$ \\ 1. Key Laboratory of Land Surface Pattern and Simulation, Institute of Geographic Sciences and Natural Re- \\ sources Research, CAS, Beijing 100101, China; \\ 2. University of Chinese Academy of Sciences, Beijing 100049, China; \\ 3. Henan Province Development and Reform Commission, Zhengzhou 450018, China
}

\begin{abstract}
Changes in regional moisture patterns under the impact of climate change are an important focus for science. Based on the five global climate models (GCMs) participating in the Coupled Model Intercomparison Project Phase 5 (CMIP5), this paper projects trends in the area of arid/humid climate regions of China over the next 100 years. It also identifies the regions of arid/humid patterns change and analyzes their temperature sensitivity of responses. Results show that future change will be characterized by a significant contraction in the humid region and an expansion of arid/humid transition zones. In particular, the sub-humid region will expand by $28.69 \%$ in the long term (2070-2099) relative to the baseline period (1981-2010). Under $2^{\circ} \mathrm{C}$ and $4^{\circ} \mathrm{C}$ warming, the area of the arid/humid transition zones is projected to increase from $10.17 \%$ to $13.72 \%$ of the total of China. The humid region south of the Huaihe River Basin, which is affected mainly by a future increase in evapotranspiration, will retreat southward and change to a sub-humid region. In general, the sensitivity of responses of arid/humid patterns to climate change in China will intensify with accelerating global warming.
\end{abstract}

Keywords: arid/humid patterns; climate change; sensitivity; aridity index; China

\section{Introduction}

The dynamic responses of terrestrial systems to climate change have been at the frontier for research in the discipline of geography (Wu et al., 2016). A climate zone is the synthesis of many climatic factors and is closely related to broad-scale vegetation type (Bailey, 2009). It allows both moisture and thermal conditions to be examined simultaneously for a better assessment of multivariate climate change (Grundstein, 2008). The mean global surface temperature has increased by $\sim 0.85^{\circ} \mathrm{C}\left(0.65^{\circ} \mathrm{C}-1.06^{\circ} \mathrm{C}\right)$ between the years 1880 and 2012 (IPCC, 2013). Climate scenarios project a further increase in global mean surface temperature of

Received: 2018-07-20 Accepted: 2018-09-10

Foundation: National Key Research and Development Program of China, No.2017YFC1502904; National Natural Science Foundation of China, No.41530749, No.41571043

Author: Ma Danyang (1990-), PhD, E-mail: mady.13s@igsnrr.ac.cn

"Corresponding author: Yin Yunhe (1979-), PhD and Professor, E-mail: yinyh@igsnrr.ac.cn 
$0.3^{\circ} \mathrm{C}$ to $4.8^{\circ} \mathrm{C}$ by the end of 21 st century. Accelerating climate change is projected to have major implications for climate zones and may cause significant zonal shifts (Mahlstein et al., 2013).

The impact of climate change on the spatial distribution of climate zones has become increasingly evident in recent decades at both global (Chan et al., 2015; Reid et al., 2015; Huang et al., 2016a) and regional (Gerstengarbe et al., 2009; Feng et al., 2012; Zhu et al., 2015) scales. According to observational studies, there have been significant expansions in semi-arid regions worldwide (Huang et al., 2016a), as well as poleward shifts in temperate, continental, and polar climate zones (Chan et al., 2015). Dry and wet climate zones in China have shown marked fluctuations and contrasts over the latter half of the 20th century (Yang et al., 2002). The drying trend in northern China has extended to the east and south (Ma et al., 2005). The boundary between semi-arid and sub-humid regions has likewise migrated (Zheng et al., 2013). The dynamics of climate zones have been used to evaluate the performance of climate models, based on methods such as Köppen classification (Lohmann, 1993; Gnanadesikan et al., 2006), Thornthwaite clustering (Elguindi et al., 2014), and K-means clustering (Zhang et al., 2016). Belda et al. (2015) suggested that the global climate models (GCMs) in the Coupled Model Intercomparison Project Phase 5 (CMIP5) needs to be improved to boost the performance in simulating the distribution of climate classification.

Changes in drought risk and aridity in many regions are among the primary effects anticipated under global warming (Dai, 2013; Trenberth et al., 2013; Greve et al., 2015). Changes associated with moisture conditions have great effects on the spatial and temporal distribution of arid/humid climate regions (AHCRs) (Yin et al., 2015), but quantifying those effects remains a challenge. Recent studies have reported a general consensus that projected changes in temperature and precipitation will cause considerable shifts in AHCRs over the global landmass (Hanf et al., 2012; Feng et al., 2014; Rohli et al., 2015). According to Feng et al. (2014), existing climate types will gradually shift towards warmer and drier types over 2071-2100, with notable expansion in arid and semi-arid climates by between $8.4 \%$ and $15.9 \%$. Projections of more arid and/or semi-arid regions in the 21 st century have been investigated in West Africa (Sylla et al., 2015), the Mediterranean (Gao et al., 2008; Alessandri et al., 2014), and China (Li et al., 2013; Cheng et al., 2015). As greenhouse gas emissions intensify in future, the area of bioclimatic zones prone to desertification in China will tend to increase (Ci et al., 2002). Under the high-emissions scenario, the range of Cwa (Monsoon-influenced humid subtropical climate) and Dwa (Monsoon-influenced hot-summer humid continental climate) climates in Eastern China is projected to expand (Cheng et al., 2015). Zhao et al. (2014) pointed out that arid and semi-arid areas globally will experience a significant temperature rise under various concentration pathways. Wet regions will become wetter and dry regions become drier. However, to what extent future climate change will affect regional shifts in China is still uncertain and differs from region to region.

Following these considerations, climate observations and CMIP5 GCM simulations were used in this study to estimate reference evapotranspiration based on the revised Penman-Monteith model. Combining reference evapotranspiration with precipitation, an aridity index was constructed to classify arid/humid climate types. We examined the trend in hydroclimatic variables under the high-emissions scenario and investigated the change in AHCR areas. This reveals the sensitivity of arid/humid patterns to climate change and indicates the regions that are most sensitive. The results help to understand more deeply the 
driving mechanisms responsible for variations in the land surface system, the evolution of plant communities, and the probability of desertification. They also provide a scientific foundation for developing appropriate strategies for adapting to climate change.

\section{Materials and methods}

\subsection{Data sources}

\subsubsection{Meteorological data}

We obtained quality-controlled monthly observations of maximum and minimum air temperatures, precipitation, relative humidity, sunshine duration, and wind speed from 581 meteorological stations in China for the period 1981-2010 (Figure 1). Data were provided by the National Meteorological Center of the China Meteorological Administration (CMA). Observations from individual meteorological stations were deleted from the dataset if a station was built after 1981, one station's location changed during the study period, another station was closed before 2010 , or more than $5 \%$ of the data were missing. Missing data were estimated by averaging the values obtained from the same station during other years. To meet the model input requirements, ground-based point meteorological data were interpolated on a $0.5^{\circ} \times 0.5^{\circ}$ grid using a thin-plate spline method.

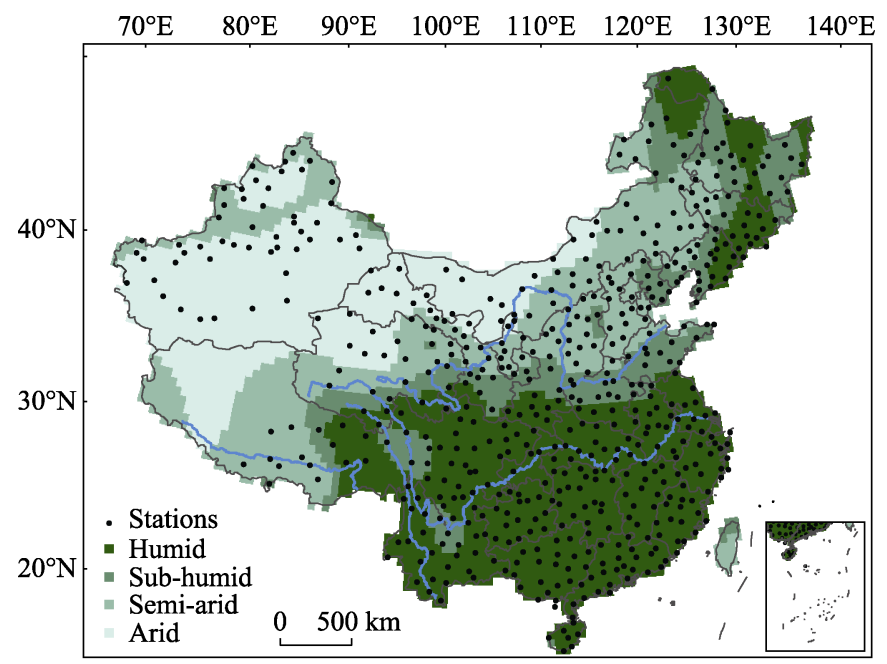

Figure 1 Distribution of 581 meteorological stations and arid/humid climate regions across China for the period 1981-2010

\subsubsection{Climate simulations}

To derive the regional mean temperature changes and corresponding spatial and temporal shifts in AHCRs across China, monthly climate data from 1950 to 2099 were utilized from the CMIP5 multi-model dataset (Taylor et al., 2012). These data are available from the Inter-Sectoral Impact Model Intercomparison Project (ISI-MIP) (Hempel et al., 2013; Warszawski et al., 2014). Five GCMs (HadGEM2-ES, IPSL-CM5A-LR, GFDL-ESM2M, MIROC-ESMCHEM, and NorESM1-M) with a horizontal resolution of $0.5^{\circ} \times 0.5^{\circ}$ participate in the ISI-MIP (Table 1). The representative concentration pathway (RCP) 8.5 scenario with radiative forcing of $\sim 8.5 \mathrm{~W} \mathrm{~m}^{-2}$ in 2100 was selected (Moss et al., 2010). This scenario provides a large range of temperature increases and is suitable for assessing the impacts of 
future climate change (Mahlstein et al., 2013; Piontek et al., 2014; Leng et al., 2015).

Table 1 Global climate models used in this study

\begin{tabular}{lclc}
\hline \multicolumn{1}{c}{ Model name } & $\begin{array}{c}\text { Original resolution } \\
\text { (latitude } \times \text { longitude })\end{array}$ & \multicolumn{1}{c}{ Modeling center } & Country \\
\hline NorESM1-M & $1.875^{\circ} \times 2.5^{\circ}$ & Norwegian Climate Centre & Norway \\
MIROC-ESM-CHEM & $2.8^{\circ} \times 2.8^{\circ}$ & $\begin{array}{l}\text { Atmosphere and Ocean Research Institute } \\
\text { The University of Tokyo), National Institute }\end{array}$ & Japan \\
& & $\begin{array}{l}\text { for Environmental Studies, and Japan } \\
\text { Agency for Marine-Earth Science and Tech- } \\
\text { nology }\end{array}$ & France \\
IPSL-CM5A-LR & $1.875^{\circ} \times 3.75^{\circ}$ & Met Office Hadley Centre & UK \\
HadGEM2-ES & $1.25^{\circ} \times 1.875^{\circ}$ & Geophysical Fluid Dynamics Laboratory & USA \\
GFDL-ESM2M & $2.0^{\circ} \times 2.5^{\circ}$ & &
\end{tabular}

Before simulation data are used to study climate change impacts, correction is recommended to reduce the bias of climate model simulations compared with the observed climate (Feng et al., 2012; Engelbrecht et al., 2016). Here, the simulated climatic variables were adjusted to have the same climatological annual mean as the real observations over China for the baseline period 1981-2010. First, the annual mean anomalies were calculated, based on differences between observed and GCM-generated data for the baseline period, for each of the five model simulations. The anomalies were then added to the scenario data to provide model inputs for the period 2011-2099 (Yin et al., 2013).

The shifts in climate zones were analyzed under the 21 st century warming levels from $1^{\circ} \mathrm{C}$ to $6^{\circ} \mathrm{C}$, relative to the baseline period. Projecting impacts for a given global warming is useful, as this is consistent with the approach of the UNFCCC (United Nations Framework Convention on Climate Change) in phrasing mitigation targets (Vautard et al., 2014; Swain et al., 2015; Roudier et al., 2016; Schleussner et al., 2016). Although global temperature thresholds provide useful information, local conditions are most important to those living with, and adapting to, the consequences of climate change (Joshi et al., 2011). Here, the years of warming over China were determined by applying an 11-year low-pass filter to the annual regional land-surface temperature anomalies, to eliminate inter-annual variability for each model. These years are generally considered to be the central points of the 11-year climatic means, as suggested by difference calculations between climate zones in China (Chen et al., 2015, Engelbrecht et al., 2016).

The multi-model ensemble (MME) means of the five models were computed. These models are assumed to be independent and are given equal weight in this study. The MME can be used to provide both a consensus representation of the climate system and a measure of the confidence to be placed in the consensus (Taylor et al., 2012). The MME approach is expected to outperform individual models in simulating global and regional climates (Pierce et al., 2009; Knutti et al., 2010; Zhao et al., 2014). The GCM ensemble means show good agreement with observed values in China and are thus able to reproduce variations in aridity during the baseline period (Yin et al., 2015).

\subsection{Arid/humid zone classification}

Many previous studies have relied on Köppen climate classification schemes (Crosbie et al., 2012; Chan et al., 2016; Engelbrecht et al., 2016), based primarily on temperature and pre- 
cipitation. The complex interplay of water supply and demand, including both precipitation (P) and reference evapotranspiration $\left(\mathrm{ET}_{\mathrm{o}}\right)$, is critical for projecting changes in dryness (Cook et al., 2014; Greve et al., 2015; Mcevoy et al., 2016) and dryland dynamics (Huang et al., 2016b). The aridity index (AI), usually expressed as the ratio between $\mathrm{ET}_{\mathrm{o}}$ and $\mathrm{P}$ (Budyko, 1974; Wu et al., 2010), is widely used as an indicator of regional moisture conditions and is an effective criterion to classify AHCRs.

In general, $\mathrm{ET}_{\mathrm{o}}$ reflects the maximum water demand of an environment to maintain its water balance, and P reflects the water supply over large regions. Currently, since it is difficult to obtain observed $\mathrm{ET}_{\mathrm{o}}$ over large regions, $\mathrm{ET}_{\mathrm{o}}$ is often simulated using models. Reasonable prediction of future $\mathrm{ET}_{\mathrm{o}}$ is important to reduce uncertainty in the assessment of climate-zone shifts. One widely used method to simulate $\mathrm{ET}_{\mathrm{o}}$ is the Penman-Monteith model (Allen et al., 1998), which emphasizes the important role of radiative and aerodynamic controls on $\mathrm{ET}_{\mathrm{o}}$. It is thus more appropriate for projections of long-term drought and dryland conditions under climate change (Sherwood et al., 2014; Huang et al., 2016b). The modified Penman-Monteith model, recommended in 1998 by the Food and Agriculture Organization (hereafter the FAO56-PM model), has been applied in both arid and humid environments (Allen et al., 1998). Radiation is calculated in the model by an Ångström formula, the accuracy of which is determined by empirical coefficients within regional limits. In our previous studies, solar radiation in the FAO56-PM model was calibrated for China and proved to be suitable in representing arid/humid zones (Yin et al., 2008). Therefore, the Penman-Monteith model was again used in the present study to simulate $\mathrm{ET}_{\mathrm{o}}$ over China.

$$
E T_{\mathrm{o}}=\frac{0.408 \Delta\left(R_{\mathrm{n}}-G\right)+\gamma \frac{900}{T+273} U_{2}\left(e_{\mathrm{s}}-e_{\mathrm{a}}\right)}{\Delta+\gamma\left(1+0.34 U_{2}\right)}
$$

where $R_{\mathrm{n}}$ is the net radiation ( $\mathrm{MJ} \mathrm{m}{ }^{-2}$ ), $G$ is the soil heat flux $\left(\mathrm{MJ} \mathrm{m}^{-2}\right), \gamma$ is the psychrometric constant $\left(\mathrm{kPa}^{\circ} \mathrm{C}^{-1}\right), \Delta$ is the slope of the saturation vapor pressure curve $\left(\mathrm{kPa}{ }^{\circ} \mathrm{C}^{-1}\right), T$ is the average temperature $\left({ }^{\circ} \mathrm{C}\right), U_{2}$ is the wind speed at $2 \mathrm{~m}$ height $\left(\mathrm{m} \mathrm{s}^{-1}\right), e_{\mathrm{s}}$ is the mean saturation vapor pressure $(\mathrm{kPa})$, and $e_{\mathrm{a}}$ is the actual vapor pressure $(\mathrm{kPa})$.

Under climate change, the AI has significance for bioclimate beyond the simple association with precipitation and temperature (Moral et al., 2016). According to the study of Wu et al. (2005), AI is conventionally used to classify the land surface at a broad scale into four zones: humid, sub-humid, semi-arid, and arid. These zones are represented by specific types of natural vegetation: forest, forest steppe including meadow, steppe, and desert, respectively (Table 2).

Table 2 Criteria for demarcating the arid/humid climate regions of China according to aridity index (AI)

\begin{tabular}{ccl}
\hline Arid/humid climate region & Aridity index $\left(\mathrm{AI}=E T_{\mathrm{o}} / \mathrm{P}\right)$ & \multicolumn{1}{c}{ Natural vegetation type } \\
\hline Humid & $\mathrm{AI}<1.0$ & Forest \\
Sub-humid & $1.0 \leqslant \mathrm{AI}<1.5$ & Forest steppe (including meadow) \\
Semi-arid & $1.5 \leqslant \mathrm{AI}<4.0$ & Steppe (meadow steppe, and desert steppe) \\
Arid & $\mathrm{AI} \geqslant 4.0$ & Desert \\
\hline
\end{tabular}

\subsection{Sensitivity assessment of AHCR shifts due to warming}

The fundamental idea of sensitivity analysis is to establish a quadratic function relationship 
between changes in AHCR area and temperature increase, thereby allowing measurement of the sensitivity of AHCR shifts to warming from the slope of the quadratic curve. First, an 11-year running mean was applied to AI series on a grid scale from 2011 to 2099, to reduce the effect of short-term climate variability and improve the robustness of the results. The percentage area change in AHCRs over China was counted year by year, by determining whether climate types shift in future relative to the baseline period. Using a quadratic function, the area of AHCR shift corresponds to temperature increase according to the national mean temperature anomaly, as shown in Eq. 2. The slope of the fitted curve (Eq. 3) is the rate of area change with temperature, which is deemed to reflect the sensitivity of AHCR shifts to warming. A rate of $>0$ indicates positive sensitivity, whereas a rate of $<0$ indicates negative sensitivity.

$$
\begin{gathered}
y=a x^{2}+b x+c \\
s=2 a x+b
\end{gathered}
$$

where $y$ is the area change as a function of the regional mean temperature anomaly $x$, relative to the baseline period; $s$ is the rate of area change; $a, b$, and $c$ are parameters fitted to the model.

\section{Results}

\subsection{Future changes in $\mathrm{ET}_{0}, \mathrm{P}$, and $\mathrm{AI}$ over China}

Changes in multi-model projected $\mathrm{ET}_{\mathrm{o}}$, $\mathrm{P}$, and $\mathrm{AI}$ under the RCP8.5 scenario relative to 1981-2010 are shown in Figures 2 and 3. Generally, all three variables increase to a greater extent over the long term (2070-2099) than over the mid term (2040-2069), although regional discrepancies exist. According to the MME results, $\mathrm{ET}_{\mathrm{o}}$ is likely to increase across almost the entire country, especially in eastern areas. The increase reaches $10 \%-20 \%$ in the mid term and $>20 \%$ in the long term, for Northeast China and southern parts of the Qinling Mountains-Huaihe River Basin. $\mathrm{P}$ has a tendency to increase similar to $\mathrm{ET}_{\mathrm{o}}$ but with a different spatial pattern. $P$ tends to increase more in the north, including the Tibetan Plateau, by $>30 \%$ in the long term, compared with $<10 \%$ in the south. AI mainly increases in the southeast and decreases in the northwest. The most notable AI increase is in the middle and lower reaches of the Yangtze River and western Xinjiang, where the increase could reach 20\% in the long term. The decrease in northwestern areas is likely to be $>10 \%$ over the mid to long term. AI changes in the range of $-10 \%$ to $\sim 10 \%$ in North and Northeast China, and increases by $>10 \%$ in the east of Northeast China.

Changes in the variables differ between the five GCMs. The most notable change in AI was simulated by the IPSL-CM5A-LR model. AI is likely to increase $>20 \%$ in the long term in all areas, except in Tibet and the west of Northeast China. With the HadGEM2-ES model, AI increases slightly in the southeast coast and to the west of Xinjiang, whereas the clearest decrease of $>10 \%$ is seen in most northern parts. As changes in $E_{0}$ projected by IPSL-CM5A-LR and HadGEM2-ES are similar, the AI changes are attributed mainly to the changes in P. Relative to the baseline period, P simulated by IPSL-CM5A-LR is negative in Xinjiang and south of the Yangtze River. Therefore, the smallest increase in total $\mathrm{P}$ gave the largest increase in AI. P simulated by HadGEM2-ES is positive across almost the entire country, with a $30 \%$ increase in the long term. Therefore, the largest increase in total P led to the smallest change in AI. For both $\mathrm{ET}_{\mathrm{o}}$ and $\mathrm{P}$, the difference among GCMs in the long term 
is greater than in the mid term, and the difference in $\mathrm{P}$ is larger than that in $\mathrm{ET}_{\mathrm{o}}$.
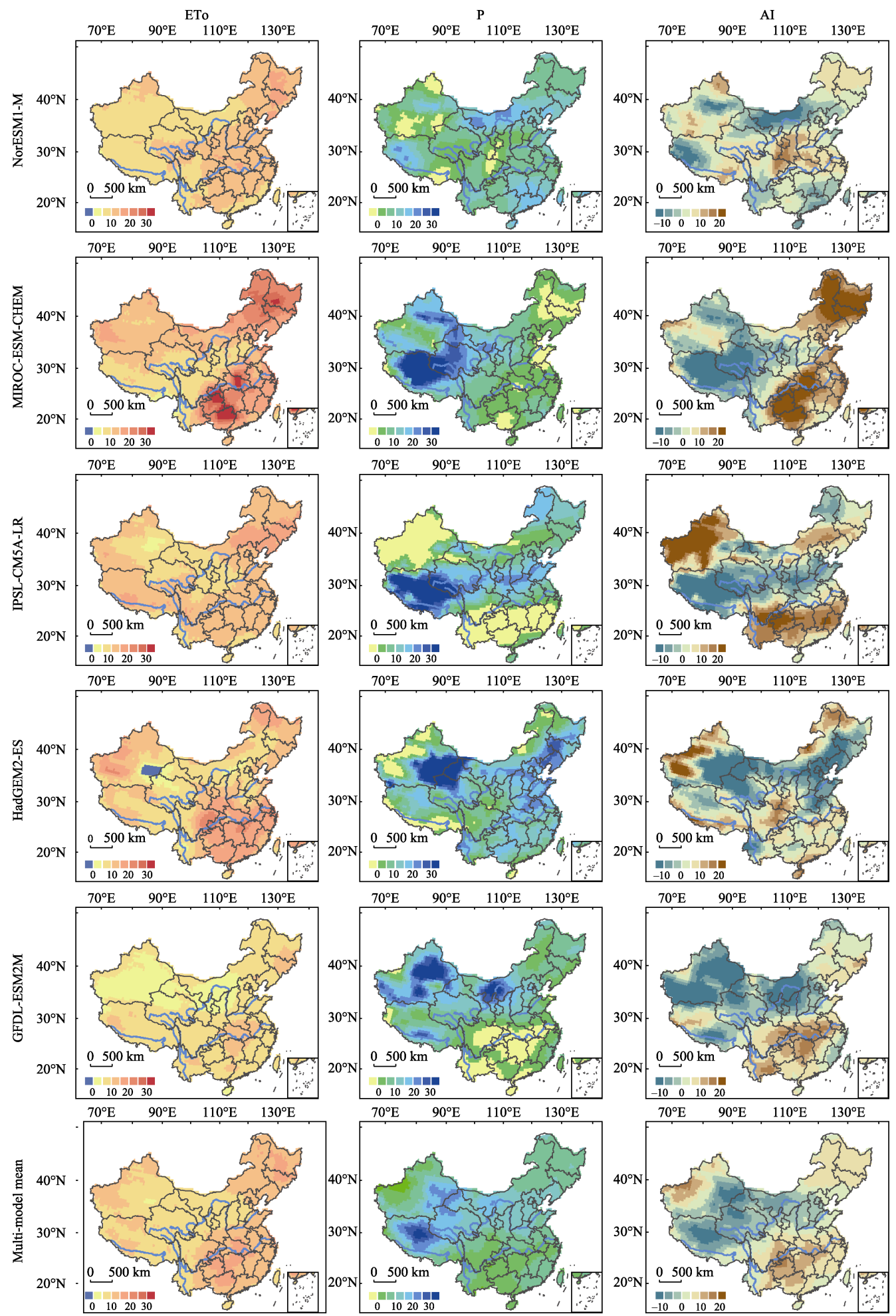

Figure 2 Percentage deviations over China in reference evapotranspiration $\left(\mathrm{ET}_{0}\right)$, precipitation $(\mathrm{P})$, and aridity index (AI) for 2040-2069, relative to the baseline period under the RCP8.5 scenario 

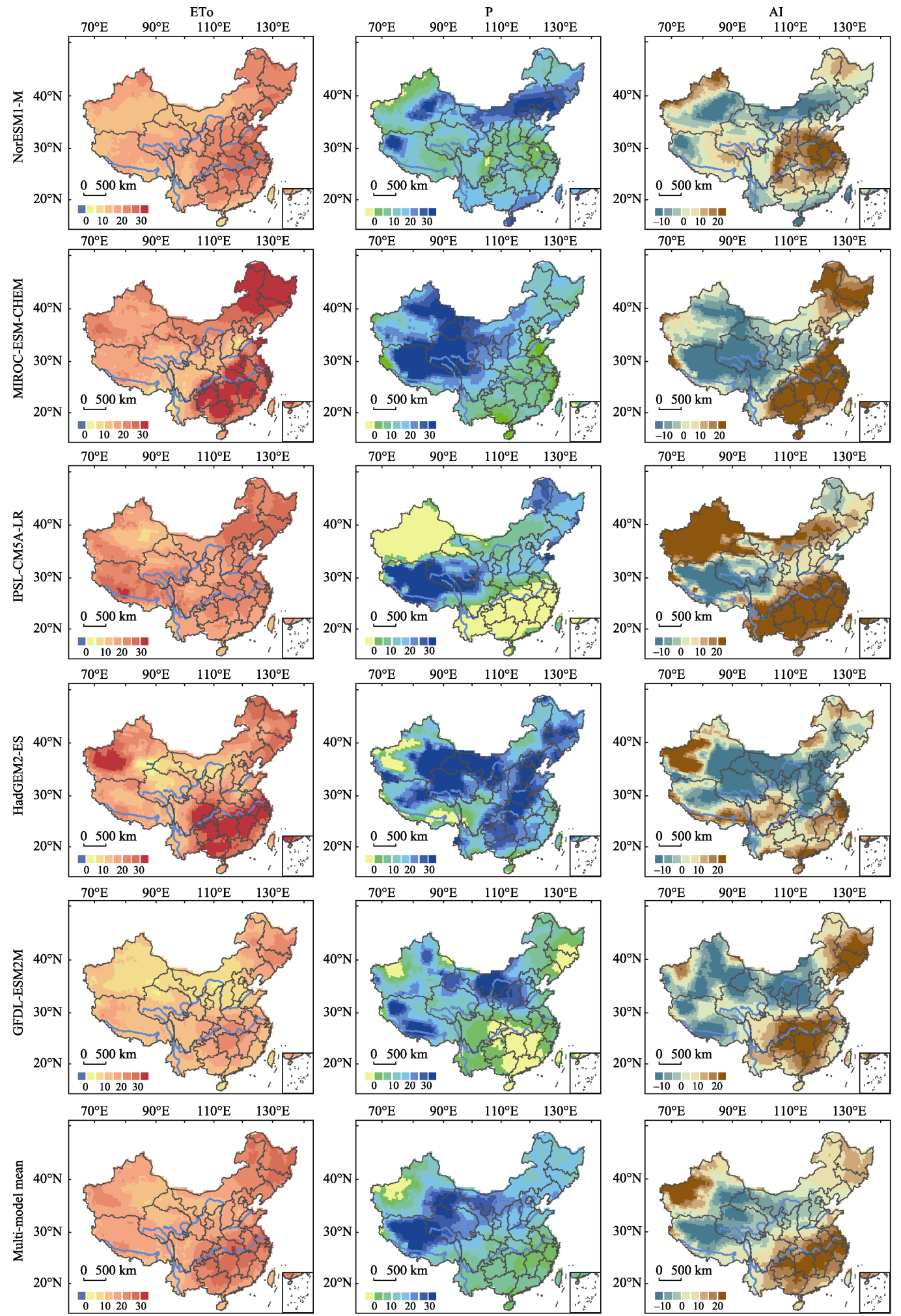

Figure 3 Percentage deviations over China in reference evapotranspiration $\left(\mathrm{ET}_{\mathrm{o}}\right)$, precipitation $(\mathrm{P})$ and aridity index (AI) for 2070-2099, relative to the baseline period under RCP8.5 


\subsection{Spatio-temporal changes in AHCRs over China}

Figure 4 shows the anomalies in areal changes in AHCRs over China relative to the baseline period 1981-2010 under RCP8.5. For the MME mean, the proportion of humid regions shows a significant reduction from 2011 to 2099 , at a rate of $-0.030 \%$ per year $(p<0.01)$. The areas of sub-humid and semi-arid regions show significant expansions at rates of $0.017 \%(\mathrm{p}<0.05)$ and $0.011 \%(\mathrm{p}<0.05)$, whereas the arid region shows no significant change. Compared with observations during the baseline period, the sizes of humid and arid regions show an average decline of $1.28 \%$ and $1.53 \%$, respectively. The sub-humid region expands by $1.98 \%$ on average, and the semi-arid region shows an average anomaly of $0.84 \%$. The differences in simulated AHCR areas between the GCMs are indicated by average standard deviations of $5.14 \%, 3.44 \%, 3.74 \%$, and $3.79 \%$ for the period $2011-2099$.
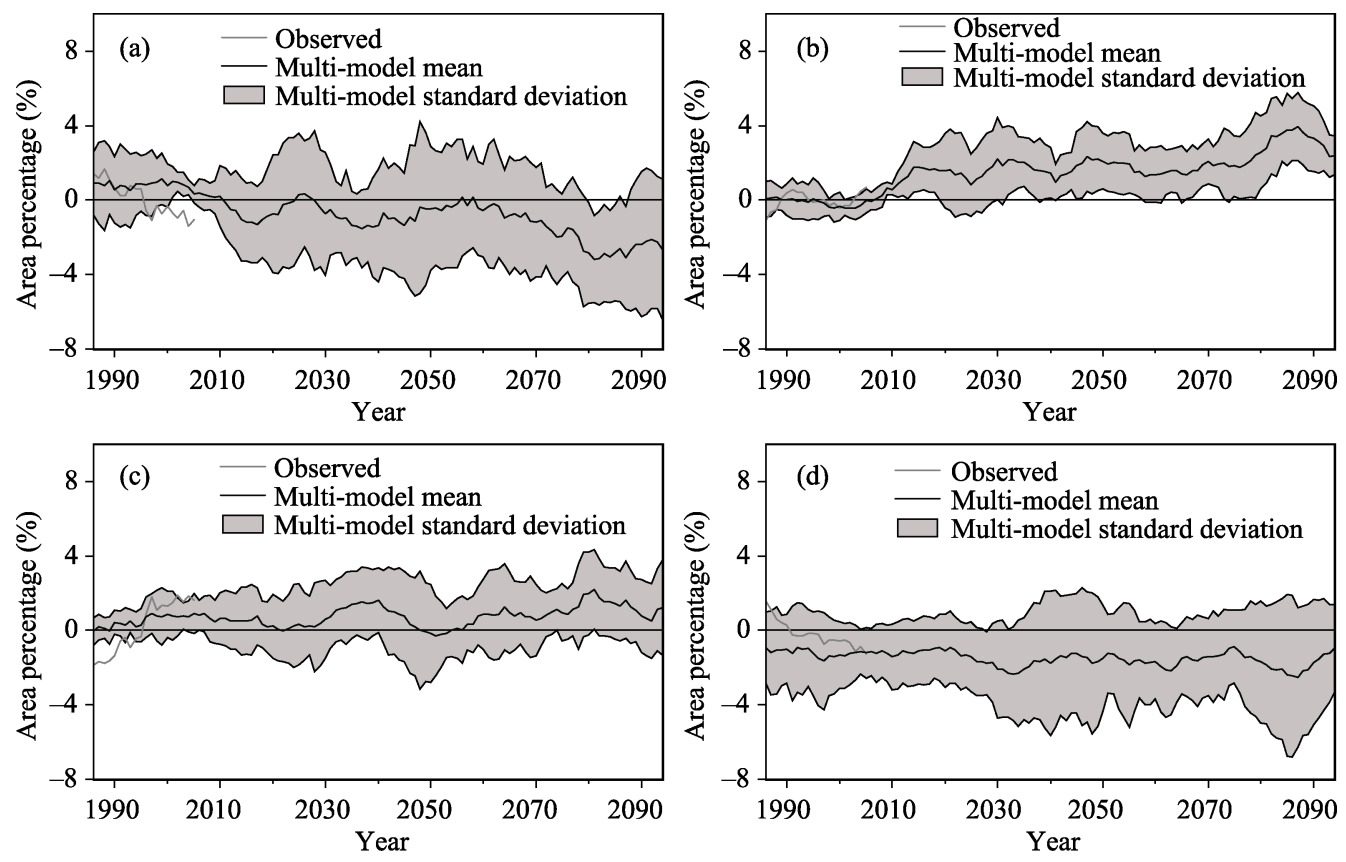

Figure 4 Area percentages (\%) of (a) humid, (b) sub-humid, (c) semi-arid, and (d) arid regions in China during the 21 st century, expressed as anomalies relative to the baseline period under RCP8.5. The time series were smoothed using an 11-year running mean

The spatial distribution of AHCRs in China from the mid to long term under RCP8.5 is shown in Figure 5, with summary statistics presented in Table 3. Both humid and arid regions are likely to shrink in future, and their respective areas are projected to reduce by $5.93 \%$ and $1.95 \%$ over 2040-2069 relative to the baseline period. The humid region will evidently shrink, as shown by its projected $12.61 \%$ decrease over 2070-2099. On the contrary, sub-humid and semi-arid regions are likely to expand, with projected increases of $16.28 \%$ and $1.38 \%$ in the mid term, respectively. The expansion of the sub-humid region reaches $28.69 \%$ in the long term. The arid region mainly decreases in the mid term, but increases over the long term. The areas of humid and sub-humid regions vary much more over the long term than over the mid term.

The multi-model simulated distributions of AHCRs across China show certain similarities 
(Figure 5). Northwest China is the main arid region, where a clear increase in future precipitation may result in a significant decrease in aridity index. Shrinkage of the arid region will occur primarily in the northwest, especially in northwest Tibet, possibly leading to a northward shift in the arid region's southern boundary (Figures 1 and 5). In addition, part of the semi-arid region north of Xinjiang may become arid, causing the entire region to shift northward. The boundary between semi-arid and sub-humid regions is projected to shift northwards in the east of the Tibetan Plateau, and shift southeastwards in Northeast China and east of the North China Plain. With the semi-arid region of Inner Mongolia shifting eastwards, the semi-arid region in Northeast China will expand.

Table 3 Percentage areas (\%) of arid/humid climate regions (AHCRs) in China for the periods 2040-2069 and 2070-2099 under RCP8.5, and the amount of change (\%) relative to the baseline period

\begin{tabular}{|c|c|c|c|c|c|c|c|c|c|}
\hline \multirow[t]{2}{*}{ GCM } & \multirow[t]{2}{*}{ Period } & \multicolumn{2}{|c|}{ Humid } & \multicolumn{2}{|c|}{ Sub-humid } & \multicolumn{2}{|c|}{ Semi-arid } & \multicolumn{2}{|c|}{ Arid } \\
\hline & & Area & Change & Area & Change & Area & Change & Area & Change \\
\hline & $1981-2010$ & 35.76 & & 13.94 & & 24.61 & & 25.69 & \\
\hline \multirow[t]{2}{*}{ NorESM1-M } & $2040-2069$ & 32.78 & -8.33 & 15.27 & 9.54 & 26.65 & 8.29 & 25.29 & -1.56 \\
\hline & 2070-2099 & 31.47 & -12 & 16.26 & 16.64 & 26.04 & 5.81 & 26.23 & 2.1 \\
\hline \multirow[t]{2}{*}{ MIROC-ESM-CHEM } & $2040-2069$ & 32.13 & -10.15 & 16.24 & 16.5 & 27.62 & 12.23 & 24.01 & -6.54 \\
\hline & 2070-2099 & 32.75 & -8.42 & 17.02 & 22.09 & 26.8 & 8.9 & 23.43 & -8.8 \\
\hline \multirow[t]{2}{*}{ IPSL-CM5A-LR } & 2040-2069 & 35.37 & -1.09 & 16.35 & 17.29 & 22.33 & -9.26 & 25.95 & 1.01 \\
\hline & 2070-2099 & 30.18 & -15.6 & 18.87 & 35.37 & 23.14 & -5.97 & 27.81 & 8.25 \\
\hline \multirow[t]{2}{*}{ HadGEM2-ES } & $2040-2069$ & 34.45 & -3.66 & 17.15 & 23.03 & 21.67 & -11.95 & 26.74 & 4.09 \\
\hline & 2070-2099 & 33.97 & -5.01 & 18.71 & 34.22 & 21.54 & -12.47 & 25.78 & 0.35 \\
\hline \multirow[t]{2}{*}{ GFDL-ESM2M } & 2040-2069 & 34.15 & -4.5 & 17.14 & 22.96 & 26.15 & 6.26 & 22.56 & -12.18 \\
\hline & 2070-2099 & 30.26 & -15.38 & 20.03 & 43.69 & 26.13 & 6.18 & 23.57 & -8.25 \\
\hline \multirow[t]{2}{*}{ Multi-model mean } & 2040-2069 & 33.64 & -5.93 & 16.21 & 16.28 & 24.95 & 1.38 & 25.19 & -1.95 \\
\hline & 2070-2099 & 31.25 & -12.61 & 17.94 & 28.69 & 24.98 & 1.5 & 25.83 & 0.54 \\
\hline
\end{tabular}

The increase in evapotranspiration will likely cause a significant rise in the aridity index over most areas in the east of China (Figures 2 and 3). Thus, the humid regions of Northeast China and in the south will shrink relative to the baseline period (Figures 1 and 5). Generally, the humid region will shift to the south. The humid region of the Huaihe River basin is projected to shrink and be gradually replaced by the sub-humid region. This means that the boundary between humid and sub-humid regions will lie in the far south. Moreover, the humid region will become sub-humid in Daxing'an, Xiaoxing'an, and the Changbai Mountains in Northeast China and part of the southeast of the country. Changes simulated by different GCMs for humid and sub-humid regions are essentially consistent, but the results concerning semi-arid and arid regions are variable. Specifically, NorESM1-M, MIROC-ESM-CHEM, and GFDL-ESM2M show that the semi-arid region mainly shrinks but the arid region mainly expands. However, the other two GCMs give contrasting results (Figure 5).

\subsection{Sensitivity of AHCR shifts to warming}

Using the 11-year running mean of the AI series from 2011 to 2099, the proportions of AHCR areas that shift relative to the baseline period under RCP8.5 were calculated. Figure 6a 

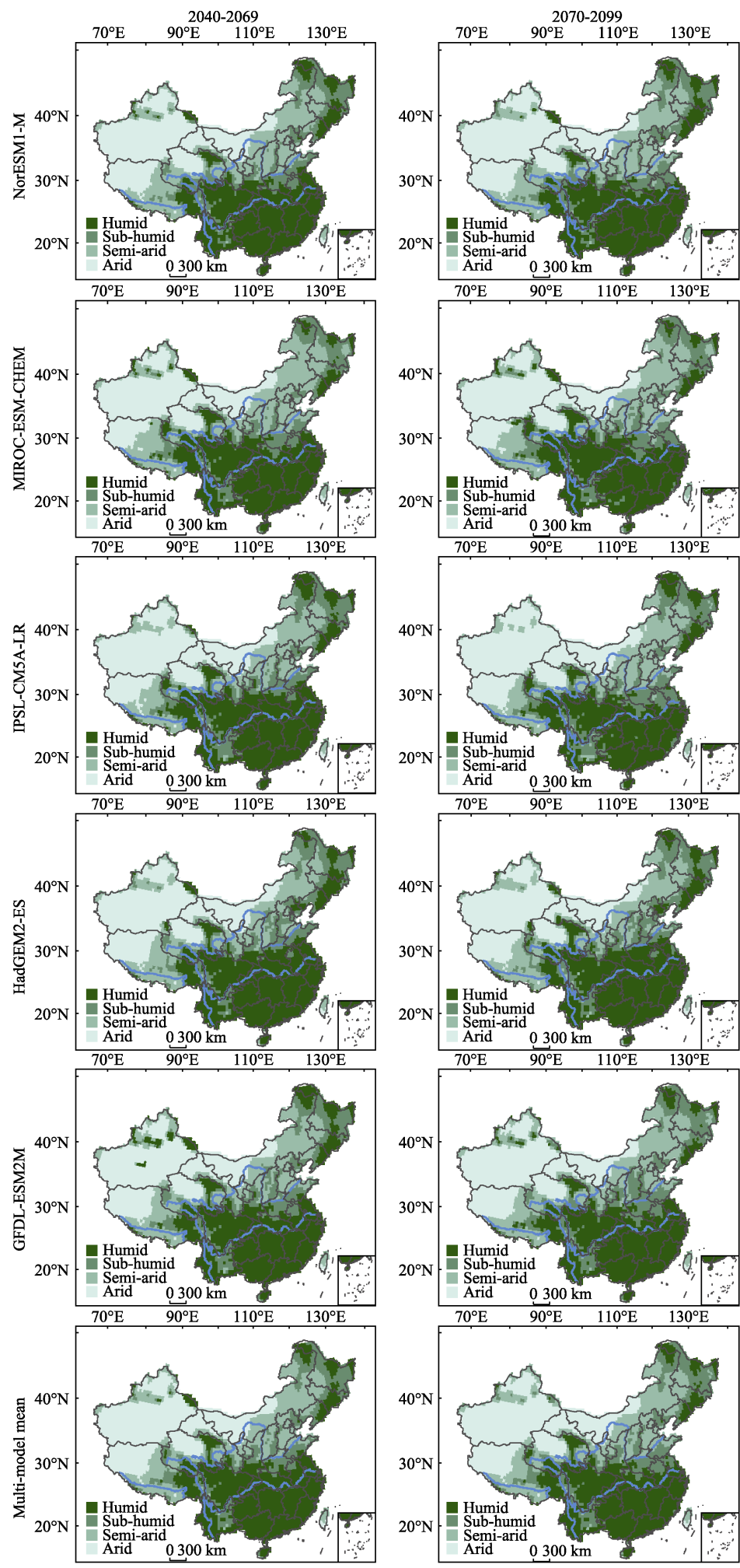

Figure 5 Spatial distribution of arid/humid climate regions (AHCRs) across China during 2040-2069 and 2070-2099 under RCP8.5 

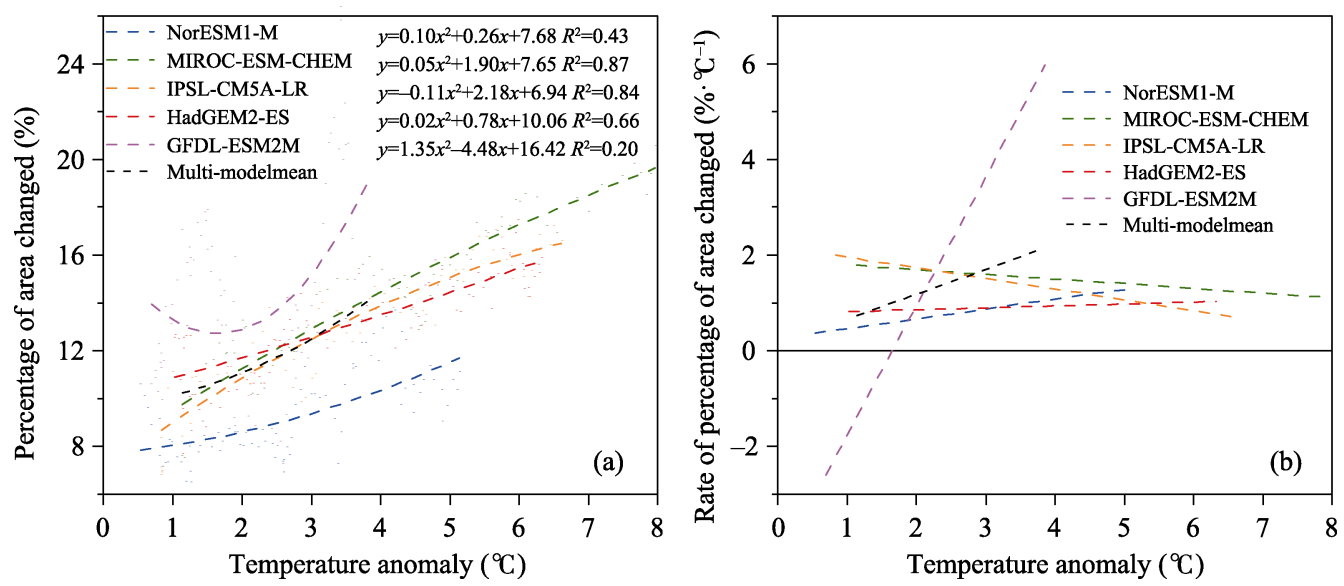

Figure 6 Shifts in arid/humid climate regions (AHCRs) across China and the rate of change with temperature anomaly relative to the baseline period under RCP8.5. (a) Percentage area change (\%). (b) Rate of percentage area change $\left(\%{ }^{\circ} \mathrm{C}^{-1}\right)$. Before quadratic curve fitting, data were smoothed using an 11-year running mean. The original data points are shown as dots in (a)

shows a quadratic curve that fits the areas of change and the temperature anomalies. Figure $6 \mathrm{~b}$ shows the corresponding rates indicating the sensitivity of AHCR shifts to warming. All shifting areas show an increasing trend as the temperature anomaly rises. Among the GCMs, the GFDL-ESM2M changes from a decreasing to an increasing trend at $\sim 2^{\circ} \mathrm{C}$. The MME results show that the percentage area affected by AHCR shifts in China increases from 10.24 $\pm 1.89 \%$ to $14.19 \pm 3.30 \%$ for the common $1.14 \%-3.87 \%$ range of temperature anomalies.

Whereas the GFDL-ESM2M rate changes from negative to positive, all other GCMs show continuously positive rates. Specifically, the changing rates of MIROC-ESM-CHEM and IPSL-CM5A-LR gradually slow down with rising temperatures, suggesting a weakening sensitivity of AHCR shifts to warming. For the MME mean, the greater the temperature increment, the higher the sensitivity of AHCR shifts. In general, the rate of change ranged from $0.73\left( \pm 1.34 \%{ }^{\circ} \mathrm{C}^{-1}\right)$ to $2.16\left( \pm 2.16 \%{ }^{\circ} \mathrm{C}^{-1}\right)$. This means that the area of AHCR shift will increase by $1.44 \%$ as the average temperature rises by $1^{\circ} \mathrm{C}$.

\subsection{AHCR shifts with $2^{\circ} \mathrm{C}$ and $4^{\circ} \mathrm{C}$ warming}

Figures 7 and 8 illustrate the changed and unchanged areas of AHCRs, as projected after $2^{\circ} \mathrm{C}$ and $4^{\circ} \mathrm{C}$ warming under RCP8.5, simulated by various GCMs. From the MME statistics (Table 4), given $2^{\circ} \mathrm{C}$ and $4^{\circ} \mathrm{C}$ warming relative to the baseline period, the following results emerge. The humid region mainly shrinks, with its area projected to reduce by $13.03 \%$ and $9.95 \%$, occupying $3.56 \%$ and $4.66 \%$ of the country, respectively. The sub-humid region considerably expands, increasing by $33.15 \%$ and $50.29 \%$, occupying $4.62 \%$ and $7.01 \%$ of the country for $2^{\circ} \mathrm{C}$ and $4{ }^{\circ} \mathrm{C}$ warming, respectively. The semi-arid region also expands, projected to increase by $13.49 \%$ and $16.65 \%$, and occupying $3.32 \%$ and $4.10 \%$ of the country, respectively. The arid region remains mostly unchanged. The AHCR areas of expansion and contraction increase from $2{ }^{\circ} \mathrm{C}$ to $4{ }^{\circ} \mathrm{C}$ warming, except for the arid region. According to the MME results, the total area of change in China is projected to increase from $10.17 \%$ for $2^{\circ} \mathrm{C}$ warming to $13.72 \%$ for $4{ }^{\circ} \mathrm{C}$ warming, bringing a further increase of $3.55 \%$.

In spatial terms, the Huaihe River Basin and Northeast China are the primary regions ex- 
periencing a shrinking humid region and expanding sub-humid region, as well as parts of Southwest China. Expansion of the semi-arid region would occur mainly in the transition zone between the sub-humid and semi-arid parts of eastern China, and in the transition zone between arid and semi-arid parts of western China. The difference between the models is projected to be larger for the reduced humid region and expanded sub-humid region. Standard deviations are $1.83 \%$ and $2.08 \%$ at $2{ }^{\circ} \mathrm{C}$ warming, and $1.20 \%$ and $1.10 \%$ at $4{ }^{\circ} \mathrm{C}$ warming, respectively. The difference between the models is projected to be the smallest in terms of the amount of arid-region change.

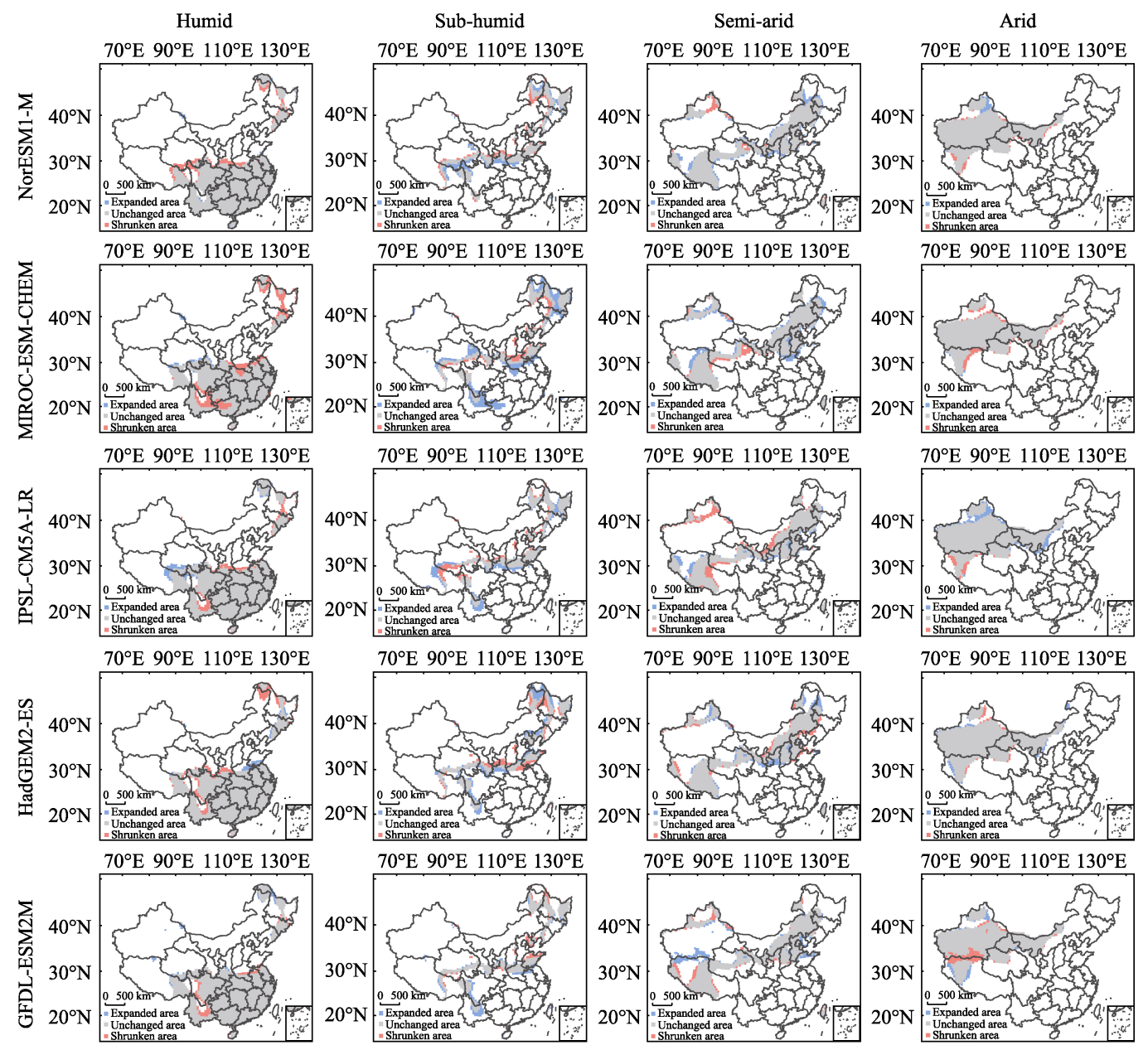

Figure 7 Spatial distribution of humid, sub-humid, semi-arid, and arid regions over China for $2^{\circ} \mathrm{C}$ warming under RCP8.5, showing changed and unchanged areas relative to the baseline period

Concerning differences between GCMs, the reduction in the humid region and expansion of the sub-humid region are both projected to be the largest by the MIROC-ESM-CHEM model, as is the total area of change $\left(13.29 \%\right.$ for $2^{\circ} \mathrm{C}$ warming and $15.42 \%$ for $4^{\circ} \mathrm{C}$ warming). For GFDL-ESM2M, although the total area of change is projected to be the smallest among models $\left(8.55 \%\right.$ for $2^{\circ} \mathrm{C}$ warming and $11.78 \%$ for $4^{\circ} \mathrm{C}$ warming), the contraction of the humid region and expansion of the sub-humid region are greater for $4^{\circ} \mathrm{C}$ warming than for $2{ }^{\circ} \mathrm{C}$ warming. The NorESM1-M model projects the largest increase $(4.87 \%)$ in the total 
area of change from $2^{\circ} \mathrm{C}$ to $4^{\circ} \mathrm{C}$ warming, caused mainly by a shift from a humid to a sub-humid climate in the Huaihe River basin, and shifts from a sub-humid to a semi-arid climate in the Loess Plateau and the North China Plain.

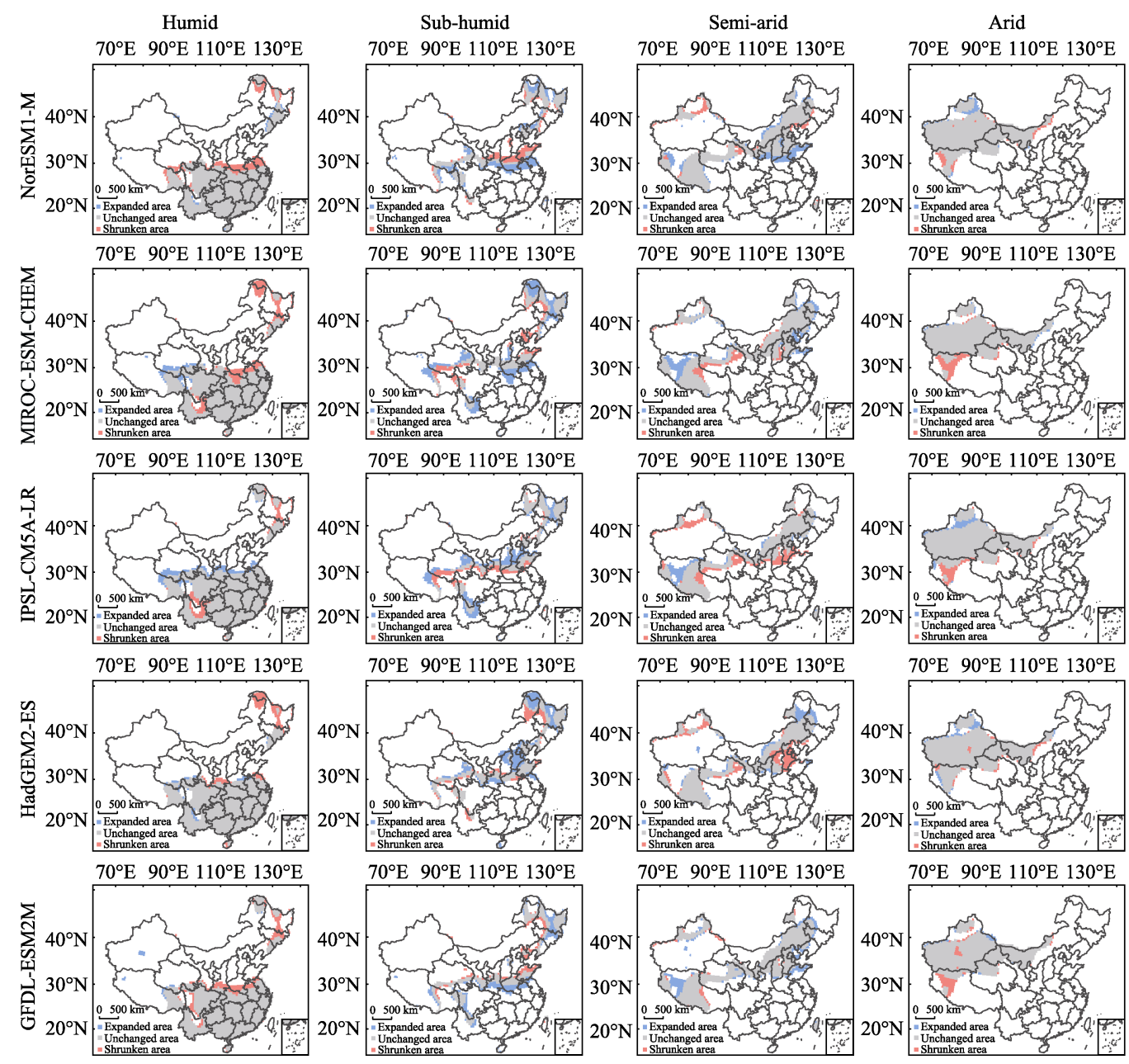

Figure 8 Spatial distribution of humid, sub-humid, semi-arid, and arid regions over China for $4{ }^{\circ} \mathrm{C}$ warming under RCP8.5, showing changed and unchanged areas relative to the baseline period

According to the models indicating change, the various climate regions are more likely to shrink or expand at their peripheries (Figure 9). Almost all of the contraction of the humid region $\left(99.73 \%\right.$ for $2{ }^{\circ} \mathrm{C}$ warming and $99.75 \%$ for $4{ }^{\circ} \mathrm{C}$ warming) would be replaced by the sub-humid region. The area of shrinkage in the sub-humid region to the east of $105^{\circ} \mathrm{E}$ would mostly become semi-arid $\left(67.86 \%\right.$ for $2^{\circ} \mathrm{C}$ warming and $72.20 \%$ for $4^{\circ} \mathrm{C}$ warming), whereas elsewhere it would mostly become humid $\left(64.77 \%\right.$ for $2{ }^{\circ} \mathrm{C}$ warming and $73.45 \%$ for $4{ }^{\circ} \mathrm{C}$ warming). Similarly, the reduced part of the semi-arid region in Northwest China would become mostly arid $\left(73.91 \%\right.$ for $2{ }^{\circ} \mathrm{C}$ warming and $82.08 \%$ for $4{ }^{\circ} \mathrm{C}$ warming), or become sub-humid elsewhere $\left(63.05 \%\right.$ for $2{ }^{\circ} \mathrm{C}$ warming and $85.03 \%$ for $4^{\circ} \mathrm{C}$ warming). In addition, over $90 \%$ of the decrease in the arid region would be replaced by a semi-arid climate. 
Table 4 Percentage change in the areas of humid, sub-humid, semi-arid, and arid regions over China for $2^{\circ} \mathrm{C}$ and $4^{\circ} \mathrm{C}$ warming under RCP 8.5 , relative to the baseline period

\begin{tabular}{|c|c|c|c|c|c|c|c|c|c|}
\hline \multirow[b]{2}{*}{ GCM } & & \multicolumn{4}{|c|}{$2^{\circ} \mathrm{C}$} & \multicolumn{4}{|c|}{$4^{\circ} \mathrm{C}$} \\
\hline & & Humid & $\begin{array}{l}\text { Sub- } \\
\text { humid }\end{array}$ & $\begin{array}{l}\text { Semi- } \\
\text { arid }\end{array}$ & Arid & Humid & $\begin{array}{l}\text { Sub- } \\
\text { humid }\end{array}$ & $\begin{array}{l}\text { Semi- } \\
\text { arid }\end{array}$ & Arid \\
\hline \multirow[t]{3}{*}{ NorESM1-M } & Expansion & 0.47 & 3.61 & 3.26 & 0.73 & 0.72 & 6.28 & 4.84 & 1.10 \\
\hline & Contraction & 3.23 & 2.54 & 1.19 & 1.09 & 5.05 & 4.07 & 2.38 & 1.44 \\
\hline & Total changed & \multicolumn{4}{|c|}{8.06} & \multicolumn{4}{|c|}{12.93} \\
\hline \multirow{3}{*}{$\begin{array}{l}\text { MIROC-ESM-C } \\
\text { HEM }\end{array}$} & Expansion & 0.87 & 8.05 & 4.24 & 0.13 & 1.64 & 8.33 & 4.92 & 0.54 \\
\hline & Contraction & 6.61 & 2.84 & 1.68 & 2.17 & 6.15 & 4.06 & 2.64 & 2.57 \\
\hline & Total changed & \multicolumn{4}{|c|}{13.29} & \multicolumn{4}{|c|}{15.42} \\
\hline \multirow[t]{3}{*}{ IPSL-CM5A-LR } & Expansion & 1.59 & 3.75 & 2.25 & 2.55 & 3.17 & 7.00 & 2.63 & 1.61 \\
\hline & Contraction & 2.50 & 2.89 & 3.85 & 0.90 & 2.95 & 3.63 & 5.74 & 2.10 \\
\hline & Total changed & \multicolumn{4}{|c|}{10.13} & \multicolumn{4}{|c|}{14.41} \\
\hline \multirow[t]{3}{*}{ HadGEM2-ES } & Expansion & 1.23 & 4.97 & 3.35 & 1.24 & 1.22 & 7.81 & 3.41 & 1.58 \\
\hline & Contraction & 3.57 & 3.68 & 2.69 & 0.86 & 4.08 & 3.33 & 5.32 & 1.30 \\
\hline & Total changed & \multicolumn{4}{|c|}{10.79} & \multicolumn{4}{|c|}{14.03} \\
\hline \multirow[t]{3}{*}{ GFDL-ESM2M } & Expansion & 1.12 & 2.72 & 3.50 & 1.21 & 0.58 & 5.62 & 4.70 & 0.88 \\
\hline & Contraction & 1.87 & 2.04 & 2.00 & 2.64 & 5.08 & 3.05 & 1.34 & 2.32 \\
\hline & Total changed & \multicolumn{4}{|c|}{8.55} & \multicolumn{4}{|c|}{11.78} \\
\hline \multirow{3}{*}{$\begin{array}{l}\text { Multi-model } \\
\text { mean }\end{array}$} & Expansion & 1.06 & 4.62 & 3.32 & 1.17 & 1.47 & 7.01 & 4.10 & 1.14 \\
\hline & Contraction & 3.56 & 2.80 & 2.28 & 1.53 & 4.66 & 3.63 & 3.48 & 1.94 \\
\hline & Total changed & \multicolumn{4}{|c|}{10.17} & \multicolumn{4}{|c|}{13.72} \\
\hline
\end{tabular}

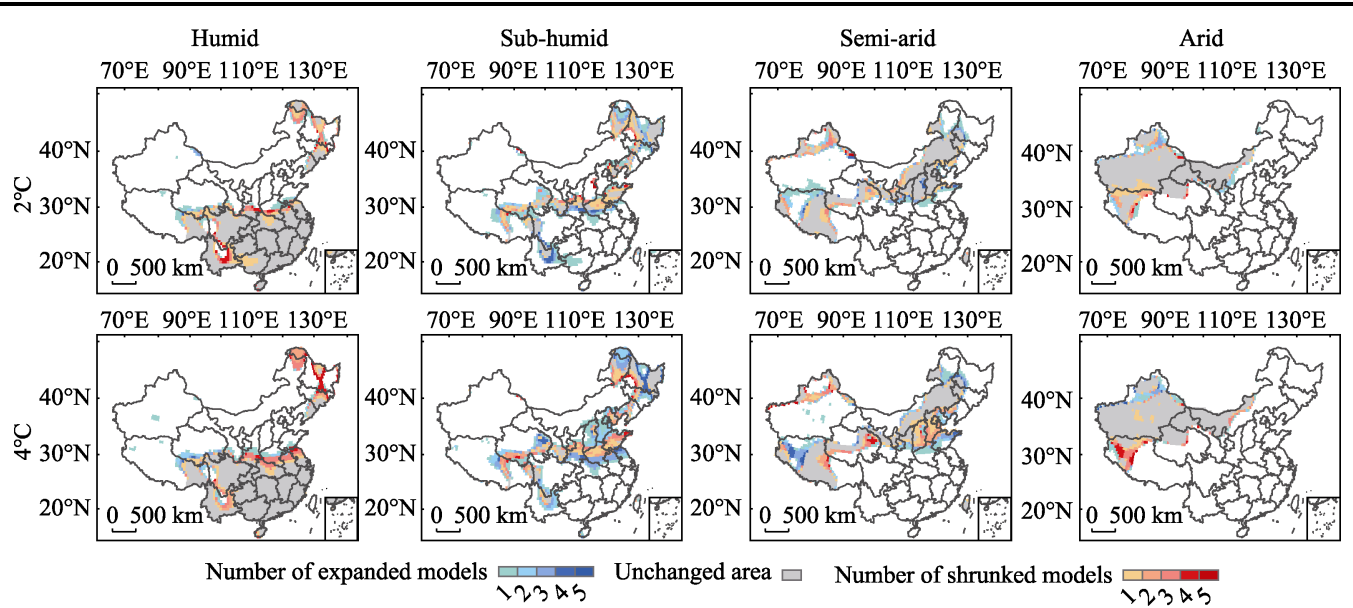

Figure 9 Spatial distribution of humid, sub-humid, semi-arid, and arid regions over China for $2{ }^{\circ} \mathrm{C}$ and $4{ }^{\circ} \mathrm{C}$ warming under RCP8.5 relative to the baseline period, showing the number of models projecting change within each region

\section{Discussion}

This study used an aridity index (AI) to classify arid/humid climate regions (AHCRs) in China. Changes in AHCR patterns under future warming were then analyzed. Results indicate that changes in the 21 st century under the RCP8.5 scenario are characterized by a sig- 
nificant contraction in the humid region and a significant expansion in the arid/humid transition zone. This is consistent with the conclusions of Wang et al. (2016), who posited that the boundaries of the East Asian climate transition zone would shift southeast and northwest, with a higher migration rate for the southern boundary. Research based on the Köppen classification system has shown that the subtropical humid region in Southeast China will contract substantially by the end of the 21 st century, relative to the end of 20 th century, particularly for the higher-emission scenarios RCP6.0 and RCP8.5 (Chan et al., 2016). Other research that used soil moisture to classify AHCRs also showed a significant contraction in the humid region of China, and a southeast expansion of the semi-arid and sub-humid climate zones in Northern China (Li et al., 2013). A global-scale study indicated that dryland areas will occupy $50 \%$ and $56 \%$ of the global land area under the RCP4.5 and RCP 8.5 scenarios, respectively, with the greatest expansion in semi-arid regions (Huang et al., 2016b). In contrast, our study shows a greater expansion in the sub-humid region. This discrepancy possibly relates to the index ranges used for climate classification, as the semi-arid definition ( $A I$ $\left.=P / E T_{\mathrm{o}}, 0.2 \leqslant A I<0.5\right)$ employed by Huang et al. (2016b) covers a wider range than that used here.

Changes in AHCR areas and boundaries are closely related to regional arid/humid trends, and are influenced by both natural factors and human activities. Based on observations and model simulations (Dai, 2013; Fu et al., 2015), some scholars regard changes in atmospheric circulation and sea-surface temperature as key drivers of land-surface precipitation change, and consider that decreasing precipitation is the main reason for the intensification of drought in many tropical and subtropical regions. However, temperature change may have additional important effects on shifts in climatic regimes as global warming continues during the 21 st century (Feng et al., 2014). Rising temperatures will lead to increasing deficits in water vapor pressure, increasing evaporation demands, and decreasing soil moisture. The mutual reinforcement of these effects will promote drought processes (Sherwood et al., 2014; Huang et al., 2016b), and thus change the regional arid/humid patterns.

Changes in vegetation cover caused by climate change or human activities may in turn affect drought trends or moisture conditions. Zeng et al. (2009) used an air-ocean-land coupling model to investigate the dynamics of vegetation composition. They found that the superposition of warming effects and albedo feedback from vegetation cover may enhance the expansion of deserts in subtropical semi-arid regions in the future. In our study, the atmospheric water-demand increase due to climate warming exceeds the precipitation increase. The tendency for a shift towards greater aridity in most humid regions in Eastern China may therefore affect the evolution of the AHCR pattern. This finding is essentially consistent with Wang et al. (2014) analysis based on the Palmer drought severity index (PDSI).

We also investigated the sensitivity of AHCR patterns to climate change in China. We found an increase in area of the arid/humid transition zone, as derived from the multi-model average, with an increase in regional average temperature. Moreover, the faster the temperature rise, the faster the response of the arid/humid transition zone. For Köppen climate zones at the global scale, changes under the RCP8.5 scenario will accelerate with rising temperatures, with the rate by the end of the 21 st century reaching approximately twice that of the early 20th century (Mahlstein et al., 2013). As a result, nearly one-third of temperate arid lands will change to subtropical arid lands over the next century, possibly accompanied by changes in vegetation type and ecosystem services (Schlaepfer et al., 2017). 
Our research also indicates how the junction between arid/humid zones in China is usually the area of significant transformation. Affected by the interaction of the East Asian summer monsoon and the mid-latitude westerly winds (Qian et al., 2009), the arid/humid transition zone extending from southwest to northeast China displays strong gradients in climate and ecosystem types (Fu, 1992). Agricultural and grazing land uses overlap. However, the ecological environment of the transition zone is fragile and highly sensitive to both climate change and human activity (Shi, 1996). As global warming intensifies, the $\mathrm{arid} /$ humid transition zone may face a growing risk of natural disasters, land degradation, and desertification (Huang et al., 2016b; Wang et al., 2016). Jiang et al. (2017) found that the sub-humid and semi-arid regions are similarly sensitive to climate change under the RCP4.5 scenario, that climate-sensitive regions will expand in China, and that humid regions will change to sub-humid regions in future.

Accurate climate modeling is crucial for simulating changes in the geographical distribution and areas of various climatic types (Zhang et al., 2016). Model uncertainty is one source of general uncertainty in climate prediction, and the discrepancies between models vary with time, space, and amount of warming (Mahlstein et al., 2013; Chen et al., 2015; Belda et al., 2016). Mahlstein et al. (2013) posited that under the RCP8.5 scenario, 20\% of the world's land area will experience a change in Köppen climate zone by the end of this century. Results vary from $17 \%$ to $27 \%$ for individual models, and the discrepancies between models increase with higher global average temperatures. For multi-model simulations, Belda et al. (2016) showed that the difference was the smallest for desert climates, the largest for northern and tundra climates, and that scenario RCP8.5 resulted in a greater difference than RCP4.5. Chen et al. (2015) found that for simulations of extreme temperature and precipitation indices in China, the uncertainty increases over time. Furthermore, the contribution of scenario uncertainty will exceed climate-model uncertainty towards the end of the century. In a study of future AHCR change in China, Yin et al. (2015) noted that aridity index values show a stronger volatility and a weaker trend compared with other climatic factors such as temperature, precipitation, and potential evapotranspiration, and that the difference between models is relatively small. Based on the corrected aridity index, the present study found that multi-model difference in humid zone variation in China is slightly larger than that for the three drier climate zones.

\section{Conclusions}

We combined climate observation data, CMIP5 GCM forecast data, and simulated reference evapotranspiration $\left(\mathrm{ET}_{\mathrm{o}}\right)$ data based on the revised Penman-Monteith model to calculate aridity index (AI) values across China. Projected spatial patterns of arid/humid zones corresponding to different levels of climate warming were then mapped. By analyzing future changes in the areas covered by arid/humid zones and their sensitivity to temperature increase, the following main conclusions were arrived at.

On the whole, $\mathrm{ET}_{\mathrm{o}}$, $\mathrm{P}$, and $\mathrm{AI}$ all increase under the RCP8.5 scenario, relative to the baseline period 1981-2010. The $\mathrm{ET}_{\mathrm{o}}$ increment is high in the east and low in the west, whereas the $\mathrm{P}$ increment is high in the north and low in the south. The AI increases in the southeast and decreases in the northwest. The projected amount of change differs between models, but is generally greater in the long term (2070-2099) than in the mid term (2040-2069). The degree of change in evapotranspiration is generally higher than that for precipitation. This 
may result in a humid to sub-humid transition for the southern part of the Huaihe River Basin.

During the 21 st century, the humid region will contract significantly $(p<0.01)$, whereas the sub-humid and semi-arid regions will expand $(\mathrm{p}<0.05)$. Compared with observed values for the baseline period, the sub-humid region will change the most. Its percentage of the national land area in China will increase at an average rate of $1.98 \%$, to expand by $28.69 \%$ in the long term. The humid region will contract in Eastern China, causing a southward shift in the boundary between humid and sub-humid zones in the Huaihe River basin, a southeastward shift in the boundary between sub-humid and semi-arid zones in North and Northeast China. In contrast, aridity will decrease in Western China, causing a northward shift in the boundary between arid and semi-arid zones.

Under the RCP8.5 scenario, areal changes in arid/humid zones according to the multi-model mean will continue increasing with rising temperature. For most GCMs, the temperature sensitivity of changes in arid/humid climate regions will gradually increase as the temperature anomaly increases. In general, the humid region will mainly contract, whereas sub-humid and semi-arid regions are mainly projected to expand. The national total area of land experiencing such changes will increase from $10.17 \%$ for $2{ }^{\circ} \mathrm{C}$ warming to $13.72 \%$ for $4^{\circ} \mathrm{C}$ warming.

\section{References}

Alessandri A, de Felice M, Zeng N et al., 2014. Robust assessment of the expansion and retreat of Mediterranean climate in the 21st century. Scientific Reports, 4(3): 7211. doi: 10.1038/srep07211.

Allen R G, Pereira L S, Raes D et al., 1998. Crop Evapotranspiration: Guidelines for Computing Crop Water Requirements. United Nations Food and Agriculture Organization, Rome.

Bailey R G, 2009. Ecosystem Geography: From Ecoregions to Sites. New York: Springer-Verlag.

Belda M, Holtanová E, Halenka T et al., 2015. Evaluation of CMIP5 present climate simulations using the Köppen-Trewartha climate classification. Climate Research, 64(3): 201-212.

Belda M, Holtanová E, Kalvová J et al., 2016. Global warming-induced changes in climate zones based on CMIP5 projections. Climate Research, 71(1): 17-31.

Budyko M I, 1974. Climate and Life. New York: Academic Press.

Chan D, Wu Q G, 2015. Significant anthropogenic-induced changes of climate classes since 1950. Scientific Reports, 5: 13487. doi: 10.1038/srep13487.

Chan D, Wu Q G, Jiang G X et al., 2016. Projected shifts in Köppen climate zones over China and their temporal evolution in CMIP5 multi-model simulations. Advances in Atmospheric Sciences, 33(3): 283-293.

Chen H P, Sun J Q, 2015. Changes in climate extreme events in China associated with warming. International Journal of Climatology, 35(10): 2735-2751.

Cheng Z G, Zhang Y M, Xu Y, 2015. Projection of climate zone shifts in the 21st century in China based on CMIP5 models data. Climate Change Research, 11(2): 93-101. (in Chinese)

Ci L J, Yang X H, Chen Z X, 2002. The potential impacts of climate change scenarios on desertification in China. Earth Science Frontiers, 9(2): 287-294. (in Chinese)

Cook B I, Smerdon J E, Seager R et al., 2014. Global warming and 21 st century drying. Climate Dynamics, 43(9/10): 2607-2627.

Crosbie R S, Pollock D W, Mpelasoka F S et al., 2012. Changes in Köppen-Geiger climate types under a future climate for Australia: Hydrological implications. Hydrology \& Earth System Sciences, 16(9): 3341-3349.

Dai A, 2013. Increasing drought under global warming in observations and models. Nature Climate Change, 3(1): $52-58$.

Elguindi N, Grundstein A, Bernardes S et al., 2014. Assessment of CMIP5 global model simulations and climate change projections for the 21 st century using a modified Thornthwaite climate classification. Climatic Change, 122(4): 523-538.

Engelbrecht C J, Engelbrecht F A, 2016. Shifts in Köppen-Geiger climate zones over southern Africa in relation to key global temperature goals. Theoretical \& Applied Climatology, 123(1/2): 247-261.

Feng S, Ho C H, Hu Q et al., 2012. Evaluating observed and projected future climate changes for the Arctic using 
the Köppen-Trewartha climate classification. Climate Dynamics, 38(7/8): 1359-1373.

Feng S, Hu Q, Huang W et al., 2014. Projected climate regime shift under future global warming from multi-model, multi-scenario CMIP5 simulations. Global \& Planetary Change, 112(1): 41-52.

Fu C, 1992. Transitional Climate Zones and Biome Boundaries: A Case Study from China. New York: Springer.

Fu Y H, Zhao H, Piao S et al., 2015. Declining global warming effects on the phenology of spring leaf unfolding. Nature, 526(7571): 104. doi: 10.1038/nature15402.

Gao X J, Giorgi F, 2008. Increased aridity in the Mediterranean region under greenhouse gas forcing estimated from high resolution simulations with a regional climate model. Global \& Planetary Change, 62(3): 195-209.

Gerstengarbe F W, Werner P C, 2009. A short update on Koeppen climate shifts in Europe between 1901 and 2003. Climatic Change, 92(1/2): 99-107.

Gnanadesikan A, Stouffer R J, 2006. Diagnosing atmosphere-ocean general circulation model errors relevant to the terrestrial biosphere using the Köppen climate classification. Geophysical Research Letters, 33(22): 2832-2849.

Greve P, Seneviratne S I, 2015. Assessment of future changes in water availability and aridity. Geophysical Research Letters, 42(13): 5493-5499.

Grundstein A, 2008. Assessing climate change in the contiguous United States using a modified Thornthwaite climate classification scheme. Professional Geographer, 60(3): 398-412.

Hanf F, Körper J, Spangehl T et al., 2012. Shifts of climate zones in multi-model climate change experiments using the Köppen climate classification. Meteorologische Zeitschrift, 21(2): 111-123.

Hempel S, Frieler K, Warszawski L et al., 2013. A trend-preserving bias correction - The ISI-MIP approach. Earth System Dynamics, 4(2): 219-236.

Huang J P, Ji M X, Xie Y K et al., 2016a. Global semi-arid climate change over last 60 years. Climate Dynamics, 46(3/4): 1131-1150.

Huang J P, Yu H P, Guan X D et al., 2016b. Accelerated dryland expansion under climate change. Nature Climate Change, 6(2): 166-171.

IPCC, 2013. Climate Change 2013: The Physical Science Basis. Contribution of Working Group I to the Fifth Assessment Report of the Intergovernmental Panel on Climate Change. Cambridge, United Kingdom and New York, USA: Cambridge University Press.

Jiang J, Jiang D B, Lin Y H, 2017. Changes and projection of dry/wet areas over China. Chinese Journal of Atmospheric Sciences, 41(1): 43-56. (in Chinese)

Joshi M, Hawkins E, Sutton R et al., 2011. Projections of when temperature change will exceed $2^{\circ} \mathrm{C}$ above pre-industrial levels. Nature Climate Change, 1(8): 407-412.

Knutti R, Furrer R, Tebaldi C et al., 2010. Challenges in combining projections from multiple climate models. Journal of Climate, 23(10): 2739-2758.

Leng G Y, Tang Q H, Rayburg S, 2015. Climate change impacts on meteorological, agricultural and hydrological droughts in China. Global \& Planetary Change, 126: 23-34.

Li M X, Ma Z G, 2013. Soil moisture-based study of the variability of dry-wet climate and climate zones in China. Chinese Science Bulletin, 58(Suppl.1): 531-544.

Lohmann R, 1993. The Koppen climate classification as a diagnostic tool for general circulation models. Climate Research, 3(3): 177-193.

Ma Z G, Fu C B, Dan L, 2005. Decadal variations of arid and semi-arid boundary in China. Chinese Journal of Geophysics, 48(3): 519-525. (in Chinese)

Mahlstein I, Daniel J S, Solomon S, 2013. Pace of shifts in climate regions increases with global temperature. Nature Climate Change, 3(8): 739-743.

Mcevoy D J, Huntington J L, Mejia J F et al., 2016. Improved seasonal drought forecasts using reference evapotranspiration anomalies. Geophysical Research Letters, 43(1): 377-385.

Moral F J, Paniagua L L, Rebollo F J et al., 2016. Spatial analysis of the annual and seasonal aridity trends in Extremadura, southwestern Spain. Theoretical \& Applied Climatology, 130(3/4): 917-932.

Moss R H, Edmonds J A, Hibbard K A et al., 2010. The next generation of scenarios for climate change research and assessment. Nature, 463(7282): 747-756.

Pierce D W, Barnett T P, Santer B D et al., 2009. Selecting global climate models for regional climate change studies. Proceedings of the National Academy of Sciences, 106(21): 8441-8446.

Piontek F, Müller C, Pugh T A et al., 2014. Multisectoral climate impact hotspots in a warming world. Proceedings of the National Academy of Sciences, 111(9): 3233-3238.

Qian W H, Ding T, Hu H R et al., 2009. An overview of dry-wet climate variability among monsoon-westerly regions and the monsoon northernmost marginal active zone in China. Advances in Atmospheric Sciences, 
26(4): 630-641.

Reid P C, Hari R E, Beaugrand G et al., 2015. Global impacts of the 1980s regime shift. Global Change Biology, 22(2): 682-703.

Rohli R V, Joyner T A, Reynolds S J et al., 2015. Globally extended Köppen-Geiger climate classification and temporal shifts in terrestrial climatic types. Physical Geography, 36(2): 142-157.

Roudier P, Andersson J C M, Donnelly C et al., 2016. Projections of future floods and hydrological droughts in Europe under a $+2{ }^{\circ} \mathrm{C}$ global warming. Climatic Change, 135(2): 341-355.

Schlaepfer D R, Bradford J B, Lauenroth W K et al., 2017. Climate change reduces extent of temperate drylands and intensifies drought in deep soils. Nature Communications, 8: 14196. doi: 10.1038/ncomms14196.

Schleussner C F, Lissner T K, Fischer E M et al., 2016. Differential climate impacts for policy-relevant limits to global warming: the case of $1.5^{\circ} \mathrm{C}$ and $2^{\circ} \mathrm{C}$. Earth System Dynamics, 7(2): 327-351.

Sherwood S, Fu Q, 2014. A drier future? Science, 343(6172): 737-739.

Shi Z T, 1996. Regional characters of natural disaster in marginal monsoon belt of China. Journal of Arid Land Resources \& Environment, 10(4): 1-7. (in Chinese)

Swain S, Hayhoe K, 2015. CMIP5 projected changes in spring and summer drought and wet conditions over North America. Climate Dynamics, 44(9/10): 2737-2750.

Sylla M B, Elguindi N, Giorgi F et al., 2015. Projected robust shift of climate zones over West Africa in response to anthropogenic climate change for the late 21st century. Climatic Change, 134(1/2): 1-13.

Taylor K E, Stouffer R J, Meehl G A, 2012. An overview of CMIP5 and the experiment design. Bulletin of the American Meteorological Society, 93(4): 485-498.

Trenberth K E, Dai A, van der Schrier G et al., 2013. Global warming and changes in drought. Nature Climate Change, 4(1): 17-22.

Vautard R, Gobiet A, Sobolowski S et al., 2014. The European climate under a $2{ }^{\circ} \mathrm{C}$ global warming. Booklist, $9(3)$ : 034006. doi: 10.1088/1748-9326/9/3/034006.

Wang L, Chen W, 2014. A CMIP5 multimodel projection of future temperature, precipitation, and climatological drought in China. International Journal of Climatology, 34(6): 2059-2078.

Wang L, Chen W, Huang G et al., 2016. Changes of the transitional climate zone in East Asia: past and future. Climate Dynamics, 49(4): 1463-1477.

Warszawski L, Frieler K, Huber V et al., 2014. The Inter-Sectoral Impact Model Intercomparison Project (ISI-MIP): Project framework. Proceedings of the National Academy of Sciences, 111(9): 3228-3232.

Wu S H, Yin Y H, Zheng D et al., 2005. Aridity/humidity status of land surface in China during the last three decades. Science in China Ser D Earth Sciences, 48(9): 1510-1518.

Wu S H, Yin Y H, Zheng D et al., 2010. Moisture conditions and climate trends in China during the period 1971-2000. International Journal of Climatology, 26(2): 193-206.

Wu S H, Yin Y H, Zheng D et al., 2016. Advances in terrestrial system research in China. Journal of Geographical Sciences, 26(7): 791-802.

Yang J P, Ding Y J, Chen R S et al., 2002. The interdecadal fluctuation of dry and wet climate boundaries in China in recent 50 years. Acta Geographica Sinica, 57(6): 655-661. (in Chinese)

Yin Y H, Ma D Y, Wu S H et al., 2015. Projections of aridity and its regional variability over China in the mid-21st century. International Journal of Climatology, 35(14): 4387-4398.

Yin Y H, Wu S H, Zhao D S, 2013. Past and future spatiotemporal changes in evapotranspiration and effective moisture on the Tibetan Plateau. Journal of Geophysical Research: Atmospheres, 118(19): 10850-10860.

Yin Y H, Wu S H, Zheng D et al., 2008. Radiation calibration of FAO56 Penman-Monteith model to estimate reference crop evapotranspiration in China. Agricultural Water Management, 95(1): 77-84.

Zeng N, Yoon J H, 2009. Expansion of the world's deserts due to vegetation-albedo feedback under global warming. Geophysical Research Letters, 36(17): L17401.

Zhang X L, Yan X D, 2016. Deficiencies in the simulation of the geographic distribution of climate types by global climate models. Climate Dynamics, 46(9/10): 2749-2757.

Zhao T B, Chen L, Ma Z G, 2014. Simulation of historical and projected climate change in arid and semiarid areas by CMIP5 models. Science Bulletin, 59(4): 412-429.

Zheng J Y, Bian J J, Ge Q S et al., 2013. The climate regionalization in China for 1981-2010. Chinese Science Bulletin, 58(30): 3088-3099. (in Chinese)

Zhu G R, Li Y, 2015. Types and changes of Chinese climate zones from 1961 to 2013 based on Köppen climate classification. Arid Land Geography, 38(6): 1121-1132. (in Chinese) 